\title{
The Politics of Responsibility
}

\section{Contribution to debate on 'The Future of Conservatism' The European, $27^{\text {th }}$ March, 2012}

\author{
http://theeuropean-magazine.com/597-ohara-kieron/598-the-future-of-conservatism
}

\author{
Kieron O'Hara \\ Web and Internet Science Group \\ Electronics and Computer Science \\ University of Southampton \\ Highfield \\ Southampton SO17 1BJ \\ United Kingdom \\ kmo@ecs.soton.ac.uk
}

Can conservatism make a distinctive contribution to the politics of crisis? My answer is 'yes', but we should be clear that it cannot solve our problems overnight.

Sober realism is important because we are heading for a period of enforced austerity and low growth. Individuals, companies and countries will have to reduce levels of debt. On top of this we will have to save even more to finance pensions and long-term healthcare. Lack of growth will mean more must be saved than previously planned because we can no longer expect soaring stock markets to boost our wealth. Meanwhile investment will fall, because banks will have to increase their capital holdings (sensibly) and therefore lend less. The 'baby-boom' generation will draw down on savings and assets, decreasing their value, while growth in emerging markets will keep commodity prices high. And underlying all this are the unquantifiable, but in my opinion real, risks of climate change.

The conservative's insight is that we never know enough. Society is too complex and dynamic; we can't foresee the consequences of policy. Change is therefore risky. Theory has its purpose, but should be kept in its place. The credit glut that followed the financial reforms in the UK and elsewhere in the 1980s is perhaps our major current problem. Economists will tell you that the Modigliani-Miller Theorem shows that it makes no difference whether investment is funded by debt or by equity. Conservatives reply: 'do you trust your eyes, or economic theorems?'

Economic growth is not a right. It needs to be earned. Governments should reform labour markets, making it easier and cheaper to hire (and therefore fire) workers, particularly young people who are currently bearing the brunt of the economic slowdown. The public sector cannot go on being an employer of last resort. The inevitable costs of future trends - particularly the ageing population's requirements need to be financed by longer working lives.

In finance, conservatives should undo neo-liberal deregulation, to reduce conflicts of interest and moral hazard. There has to be a middle way between a French-style attack on all financial innovation, and a naïve UK-style belief that nothing can ever go wrong. Regulators must let banks experiment and develop new products, without being swept along with the tide when bubbles begin to develop. 
The conservative should also work toward preserving the environment with practical (possibly small-scale) action, not grand international (and unenforceable) treaties. Ensuring that those who cause environmental degradation pay for cleaning it up is better than banning particular activities thought to have bad effects, and subsidising particular technologies. But the conservative has to engage on climate change; no other ideology is able to articulate the complex politics of risk so well. Liberals ignore the risks, while socialists and greens would rather impose recession. Current conservative neglect of environmental issues is a major vulnerability.

Indeed, no ideology has a ready answer to today's politics of austerity. The demands of the media and the uncertainty of electoral cycles drive politicians to promise more, financing today's spending by tomorrow's growth. Optimism is the single European political currency, and like the euro it will be put under strain in the medium term.

But the main requirement is for individuals, companies and governments to act responsibly; that cannot be imposed by any ideology. In particular, there is an obvious mantra for European governments: if you don't want to be pushed around by the bond markets, don't borrow on the bond markets. You can either spend less money, or tax your citizens more, or (if you are not in the Eurozone) print more money. That's the choice; you can no more spend without limit than you can repeal the law of gravity. 